\title{
Anomalous Origin of the Superior Thyroid Artery from the Internal Carotid Artery
}

\author{
Adegbenro Omotuyi John Fakoya ${ }^{1 *}$, Neha Subedi ${ }^{2}$, Jennifer Beniquez Martir ${ }^{2}$, Byron Chique Carreras ${ }^{2}$, Abayomi Gbolahan \\ Afolabi $^{1}$, Thomas McCracken ${ }^{1}$ \\ ${ }^{1}$ Department of Anatomy, University of Medicine and Health Sciences, Basseterre, St. Kitts and Nevis; ${ }^{2}$ Department of \\ Anatomical Sciences, University of Medicine and Health Sciences, Basseterre, St. Kitts and Nevis
}

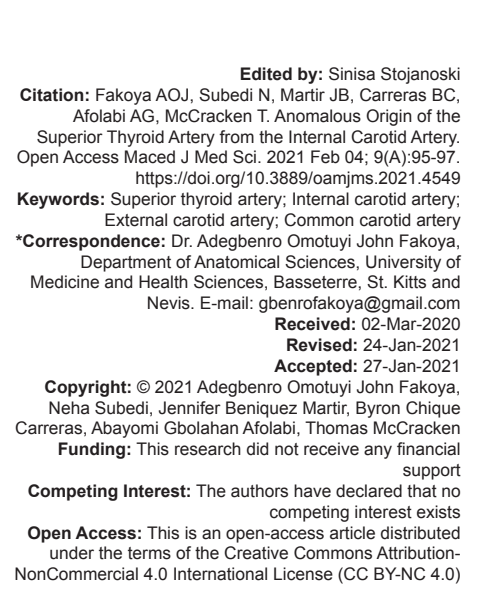

\begin{abstract}
Anatomical anomalies in the human body are common, and their description helps physicians and surgeons during treatment. This article presents the discovery of an abnormal arterial branch originating from the internal carotid artery (ICA). Typically, this artery does not give off branches until it passes through the carotid canal, but during a cadaveric dissection of a 58-year-old female, the superior thyroid artery (STA) was found to be originating from the ICA. Some common variations of the origin of the STA are the common carotid and at the bifurcation of the Common carotid, but rarely, has it been seen origination from the ICA. No known health implication of this variation has been reported, although surgeries can become difficult since the artery is used as an anatomical landmark.
\end{abstract}

\section{Introduction}

The superior thyroid artery (STA) is typically the first branch of the external carotid artery (ECA) emerging below the level of the greater horn of the hyoid bone [1]. It courses anterolateral to the thyroid and gives off the infrahyoid branch, the superior laryngeal branch, the cricothyroid branch, and the sternocleidomastoid branch of arteries [2]. The anatomy of STA, however, varies. The common variations seen are the STA branching from the common carotid artery (CCA) and the common carotid bifurcation (CCB).

Studying the variation of the STA is imperative as it has significant clinical implications for head and neck surgical procedures. STA is primarily the arterial supply for the thyroid gland, the upper larynx tissues, the skin, and neck muscles [3]. Damage to the artery can subsequently compromise these structures. STA also serves as an anatomical landmark for numerous structures. Awareness of these variations can help surgeons to accurately locate and ligate the STA to prevent accidental bleeding during thyroid surgery [1]. Furthermore, the external branch of the superior laryngeal nerve (EBSLN) is vulnerable to damage during surgical procedures as it runs medial to the STA and innervates the thyroid gland [1]. The STA is also a vital vessel for procedures such as emergency cricothyroidotomy, thyroidectomy, carotid endarterectomy, reconstructive surgery, diagnostics, and treatments of head and neck cancers such as radical neck dissections, and catheterization to deliver cancer therapeutics; therefore, there is significant clinical importance in studying the aberrations of the origins of the STA [3].

This case report provides more insight into the variations in the origin of STA by comparing data from relevant studies. This report presents a rare variation, where the STA branches off from the internal carotid artery (ICA).

A routine dissection of the carotid triangle in a 58-year-old female cadaver revealed an abnormal origin of the STA. To locate the artery, students from the University of Medicine and Health Sciences, St. Kitts and Nevis, reflected the sternohyoid and sternothyroid muscles to expose the thyroid gland. Once exposed, the 
STA was located and traced through the carotid sheath where it was discovered to be originating from the cervical segment of the ICA (Figure 1). The abnormal branch is located on the right side of the cadaver, just above the bifurcation of the CCA and inferior to the lingual artery. No other anomalies were found in this area.

\section{Discussion}

Commonly, the STA is described as the first branch originating from the ECA; however, many studies have reported variations of its origin. Underlying embryological etiology for this aberrant presentation is rarely described in literature. However, it is known that the third aortic arch, the ventral and dorsal aorta give rise to this artery [4], [5]. Additional studies have found a signaling pathway linked to tissue patterning, the Notch signaling cascade [6], [7], [8]. It is by this mechanism that embryological tissue migrates and differentiates into its adult remnant [4]. Anomalies in this pathway could explain the variability in the location of this vessel.

Multiple studies have reported a greater rate of cases where the STA was found originating from the carotid bifurcation and the CCA. A previous study performed on 300 heminecks collected from

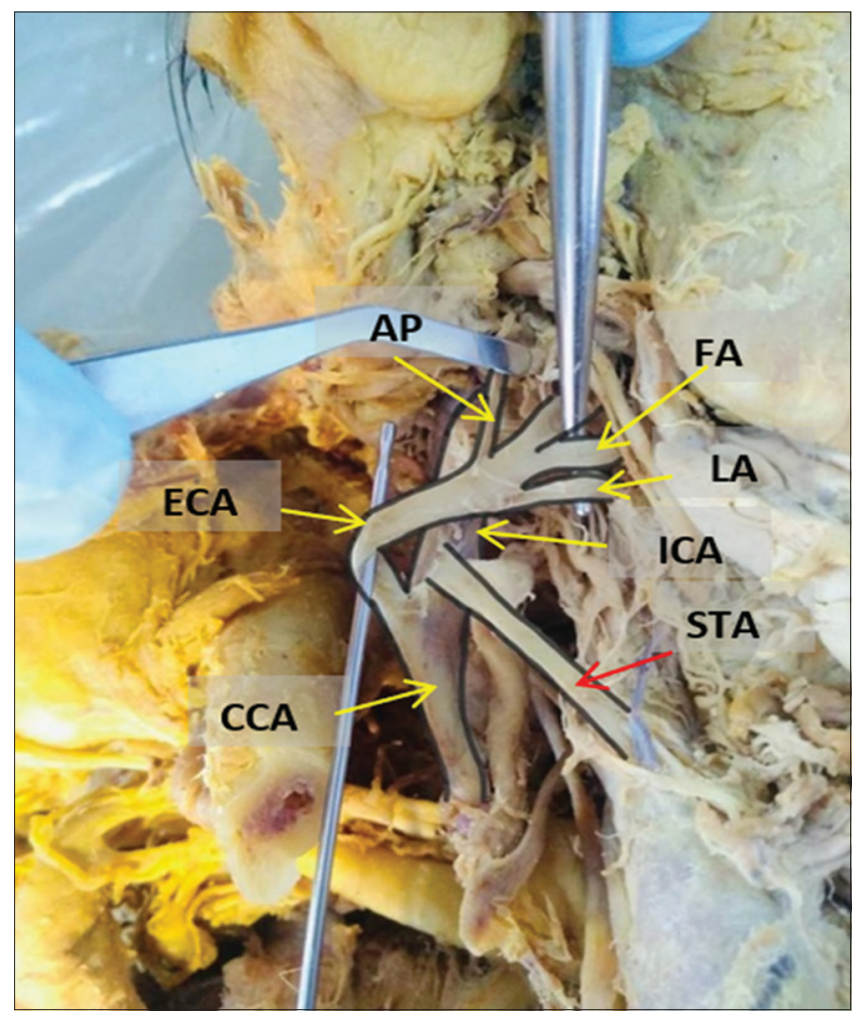

Figure 1: Bifurcation of the CCA, the red arrow indicates the anomalous vessel branching from the ICA. CCA: Common carotid artery, STA: Superior thyroid artery, ECA: External carotid artery, ICA: Internal carotid artery, LA: Lingual artery, FA: Facial artery and $A P$ : Ascending pharyngeal artery
165 cadavers demonstrated that in $49 \%$ of the cases, and the STA was found to arise at the level of the carotid bifurcation. In $27 \%$ of the cases, it was found branching from the CCA, while only $23 \%$ of the time it was shown originating from the ECA. They also noted that in $95 \%$ of the cases, this artery was shown arising from the anterior aspect of the carotid arterial tree, as seen in our case [9]. In 2011, a group of researchers stated that in $61 \%$ of the cases, the STA was found originating from carotid bifurcation, while $39 \%$ of cases presented the origin in the ECA [10]. However, in 2014, an angiographic study showed that $71.5 \%$ of cases had the STA arising from the ECA, $21.5 \%$ from the carotid bifurcation, and 1 case had the STA originating from the ICA as seen in our cadaver [11]. This report correlates with one of the most recent papers where 60 adult heminecks showed that in $88 \%$ of cases, the STA had its origin from the ECA, while $8 \%$ was found originating from the CCB [12]. With such a vast difference in its anatomical location, questions must arise about the implications these abnormalities can pose to patient care and the surgeries performed in this region.

The STA and its branches are the main arteries to be considered for any surgical procedures involving the thyroid gland, parathyroid glands, upper larynx, and neck. Trauma to the artery during surgical procedures can lead to acute hemorrhages and can be fatal [13]. STA is used as a landmark to locate the EBSLN as it commonly runs together [14]. As this nerve innervates the cricothyroid muscles, injury to it can lead to decreased vocal projection and reduced ability to produce high-frequency sounds [15]. The STA can also be useful for repurposing in reconstructive surgeries such as patching following carotid endarterectomy, and for corrective surgeries where it is used to create a microsurgical vascular anastomosis into the common carotid to aid with better arterial flow [14], [16]. Anomalies in the STA can cause it to become irrelevant in the event of a vascular graft, compromising, and complicating the correctional procedure. The STA is also crucial while considering cancers of the region. In approximately $80 \%$ of thyroid tumors, STA is the feeding artery [3]. Laryngeal cancer is also commonly supplied by the STA [13]. In cases where cancer has widespread to parts of the neck, including the carotid body, thyroid gland, parathyroid gland, hypopharynx, larynx, trachea, and esophagus, it is extracted through radical neck dissections. Rupture of the STA and its branches is a primary complication associated with the radical neck dissections, so any anomalies of the STA should be known before going into surgery to ensure better outcomes [13]. Chemotherapeutic agents are also delivered to glottic and supraglottic cancers through the SLA branch of STA [13]. An appropriate and effective catheterization technique to deliver anticancer agents is chosen based on the anatomical position of the STA [13]. Overlooking any anomaly in the origin of the STA will reduce the efficacy of cannulation for chemo-embolizations in the neck [17]. It is, therefore, 
paramount for interventional radiologists to keep the aberrant anatomy of STA in consideration while treating head and neck cancers [17]. Detailed understanding of the variations in STA anatomy is of utmost importance for surgeons and interventional radiologists to ensure safe practices and effective outcomes in surgical procedures and cancer treatments.

\section{Conclusion}

The variation of STA originating from the ICA is rarely seen and reported in literature. Therefore, its knowledge has significant implications for procedural head and neck surgeries, as well as radiological diagnostic and therapeutic procedures. The anatomical position of the STA serves as a landmark for identifying various structures in the region of the neck, including the EBSLN that runs with it. Knowledge of all of the variations in the origin of the STA, including the rare presentation in our case study is paramount to reducing iatrogenic injury and improving interventional outcomes, thus, translating to a better quality of life for the patient. Further research is needed to make conclusions on the etiology of STA variation and its physiological and health implications if any.

\section{References}

1. Dessie MA, Variations of the origin of superior thyroid artery and its relationship with the external branch of superior laryngeal nerve. PLoS One. 2018;13(5):e0197075. https://doi. org/10.1371/journal.pone.0197075

PMid:29746515

2. Motwani R, Jhajhria SK. Variant branching pattern of superior thyroid artery and its clinical relevance: A case report. J Clin Diagn Res. 2015;9(6):5-6. https://doi.org/10.7860/ jcdr/2015/12956.6065 PMid:26266110

3. Won SY. Anatomical considerations of the superior thyroid artery: Its origins, variations, and position relative to the hyoid bone and thyroid cartilage. Anat Cell Biol. 2016;49(2):138-42. https://doi.org/10.5115/acb.2016.49.2.138 PMid:27382516

4. Michalinos A, Chatzimarkos M, Arkadopoulos N, Safioleas M, Troupis T. Anatomical considerations on surgical anatomy of the carotid bifurcation. Anat Res Int. 2016;2016:6907472. https:// doi.org/10.1155/2016/6907472 PMid:27047690

5. Sadler TW. Cardiovascular system. In: Langman's Medical Embryology. $12^{\text {th }}$ ed., Ch. 13. Baltimore, MD: Lippincott Williams and Wilkins; 2012. p. 185-7.

6. Heller E, Fuchs E. Tissue patterning and cellular mechanics. J Cell Biol. 2015;211(2):219-31.

PMid:26504164

7. Reichrath J, Reichrath S. Notch signaling and tissue patterning in embryology: An introduction. Adv Exp Med Biol 2020;1218:17. https://doi.org/10.1007/978-3-030-34436-8_1 PMid:32060868

8. Fernandez-Valdivia R, Takeuchi $H$, Samarghandi A, Lopez M, Leonardi J, Haltiwanger RS, et al. Regulation of mammalian notch signaling and embryonic development by the protein O-glucosyltransferase Rumi. Development 2011;138(10):192534. https://doi.org/10.1242/dev.060020

\section{PMid:21490058}

9. Vázquez T, Cobiella R, Maranillo E, Valderrama FJ, McHanwell S, Parkin I, et al. Anatomical variations of the superior thyroid and superior laryngeal arteries. Head Neck. 2009;31(8):1078-85. https://doi.org/10.1002/hed.21077

PMid: 19340860

10. Natsis K, Raikos A, Foundos I, Noussios G, Lazaridis N, Njau SN. Superior thyroid artery origin in Caucasian Greeks: A new classification proposal and review of the literature. Clin Anat. 2011;24:699-705. https://doi.org/10.1002/ca.21181 PMid:21438023

11. Gupta P, Bhalla AS, Thulkar S, Kumar A, Mohanti BK, Thakar A, et al. Variations in superior thyroid artery: A selective angiographic study. Indian J Radiol Imaging 2014;24(1):66-71. https://doi.org/10.4103/0971-3026.130701

PMid:24851008

12. Sreedharan R, Krishna L, Shetty A. Origin of superior thyroid artery: Under the surgeon's knife. J Vasc Bras. 2018;17(4):290-5. https://doi.org/10.1590/1677-5449.004218 PMid:30787946

13. Ozgur Z, Govsa F, Celik S, Ozgur T. Clinically relevant variations of the superior thyroid artery: An anatomic guide for surgical neck dissection. Surg Radiol Anat. 2008;31(3):151-9. https:// doi.org/10.1007/s00276-008-0405-7 PMid:18754071

14. Anagnostopoulou S, Mavridis I. Emerging patterns of the human superior thyroid artery and review of its clinical anatomy. Surg Radiol Anat. 2013;36(1):33-8. https://doi.org/10.1007/ s00276-013-1149-6

PMid:23783368

15. Barczyński M, Randolph GW, Cernea CR, Dralle H, Dionigi G, Alesina PF. External branch of the superior laryngeal nerve monitoring during thyroid and parathyroid surgery: International neural monitoring study group standards guideline statement. Laryngoscope. 2013;123:S1-14. https://doi.org/10.1002/ lary.24301

16. Frick $A$, Baumeister $R G$, Fürst $H$. Vaskularisierung eines freien Jejunumtransplantates bei insuffizientem Gefässstatus am Hals*. Vascularisation of a free jejunal graft at the neck in an insufficient vascular situation. Handchir Mikrochir Plast Chir. 2002;34(1):65-8. https://doi.org/10.1055/s-2002-22101

17. Cappabianca S, Scuotto A, laselli F, di Spinazzola NP, Urraro F, Sarti G, et al. Computed tomography and magnetic resonance angiography in the evaluation of aberrant origin of the external carotid artery branches. Surg Radiol Anat. 2012;34(5):393-9. https://doi.org/10.1007/s00276-011-0926-3

PMid:22215429 